\section{Engajamento na dança: uma profissấo tratada como juvenil}

Pierre-Emmanuel SORIGNET. Danser: enquête dans les coulisses d'une vocation. Paris, La Découverte, 2010. 322 páginas.

\section{Marcílio Dantas Brandão}

Pierre-Emmanuel Sorignet é doutor em sociologia pela Escola de Altos Estudos em Ciências Sociais e pela Escola Normal Superior, ambas situadas em Paris. Atua como professor na Universidade Toulouse III. Diferentemente da maioria dos professores e pesquisadores em ciências sociais, ele dança profissionalmente há mais de dez anos. Tendo iniciado a dança aos 7 anos de idade por incentivo da mãe, afastou-se em benefício de esportes aos quais se dedicou na adolescência e voltou a dançar profissionalmente em 1993, quando integrou uma ópera contemporânea em turnê pela Alemanha. Após mais uma suspensão deste engajamento, o autor decidiu, ao longo de seus estudos doutorais (sob a orientação de G. Mauger), voltar a atuar como dançarino contemporâneo para poder pesquisar este tema a partir de métodos fundados na observação participante. Finalizando o doutorado em 2001, ele continuou seu duplo engajamento à pesquisa em ciências sociais e à dança, tendo participado em diversos espetáculos na França ao longo da última década, passando tanto por palcos pequenos e precários, como por outros grandes e prestigiados, como o Palais Chaillot.

Em 2010 publicou Danser: enquête dans les coulisses d'une vocation, sobre a profissão de dançarino na França. Integrando uma coleção que difunde textos de apoio à pesquisa de campo, a obra associa referências frequentemente apresentadas como opostas. Sob o objetivo de compreender as interaçóes entre profissionais atuantes no que Becker (1984) chamou de "mundo da dança", o autor recheou seu livro também com dados estatísticos e análises fundadas em outros métodos. Ele vai mais longe do que anuncia: dos bastidores evocados no subtítulo, passando por muitos outros lugares onde dançarinos interagem, Sorignet chega até os palcos franceses e, sobretudo, analisa a inexorável saída deste mercado de trabalho. A obra é organizada em oito capítulos, sob dois eixos: trabalho e socialização.

Para permitir a expressão pela dança, os profissionais são estimulados a exercitar seus corpos, ampliar suas possibilidades de movimento e permitir o contato com outros corpos e objetos. Isto contribui para fazer da dança uma linguagem útil, na qual as palavras são impotentes. Ao introduzir esta noção de dança como linguagem, mencionada com base em um depoimento de Pina Bausch, o autor aproxima seu objeto da tradição sociológica que procura explicar o mundo a partir da invenção de um discurso singular. A revisão da literatura sobre o tema na França o levou a constatar a primazia do estudo de estatísticas de integração num mercado onde os dançarinos desempenham papel subalterno aos coreógrafos. Os limites dessa aproximação motivaram Sorignet a pesquisar sobre esta profissão na qual o corpo é a principal ferramenta de um trabalho que sacrifica a estabilidade.

Considerada uma "profissão do espetáculo", a dança na França permite que seus profissionais utilizem um regime especial de previdência social. Segundo órgão estatal que se ocupa de estatísticas trabalhistas (DEPS, 2006), entre 1987 e 2000 o número de trabalhadores em regime temporário no mundo da dança cresceu $97 \%$ e a remuneração também aumentou $28 \%$. Entretanto, a duração de tempo de serviço reduziu significativamente, levando a um rendimento médio anual $17 \%$ inferior. Com o contínuo crescimento dos efetivos, sobreviver somente com os rendimentos oriundos deste trabalho tem sido cada vez mais difícil. ${ }^{1}$ A pesquisa de Sorignet apontou ainda que a ausência de rotina, as fortes tensōes vividas em cursos, estágios, testes, ensaios e espetáculos concorrem para marcar os corpos e as almas dos dançarinos. Os corpos alteram-se pela prática contínua e intensa de exercícios, os hábitos modificam-se devido aos diferentes usos sociais que fazem de seus corpos (Boltanski, 1971), bem como por causa de suas práticas de lazer e de suas relaçôes sociais. Segundo o autor, as oportunidades de trabalho neste mercado dependem principalmente da comunicação direta interpessoal (bouche à oreille). Para conhecê-las é preciso viver entre profissionais deste mundo. Assim, espaços profissionais e sociais se imbricam. 
A escolha por esta profissão, assim como as possibilidades de formação são socialmente marcadas. A colaboração ou resistência de familiares, amigos e professores influenciam a decisão de começar e, sobretudo, de persistir investindo na carreira. A questão de gênero merece destaque, pois os homens são mais raros e enfrentam menos dificuldades de integração profissional. Apesar da existência de espaços estatais dedicados à formação e da boa conceituação das escolas públicas de dança na França, ainda há autodidatas. Sorignet descreve com maestria os esforços para se afirmar profissionalmente, seja por meio de testes, seja pelos "encontros" entre criador e intérprete. Estas últimas estratégias são desmistificadas pela afirmação de que quando um coreógrafo decide abrir mão de testes para a seleção de dançarinos, ele se apoia em uma rede de relações oriunda da mesma "comunidade estética", isto é, compartilha com outros coreógrafos ou dançarinos experientes o ponto de vista sobre a adequação de um dançarino a um determinado espetáculo. Dessa forma, mesmo reconhecendo sua existência, o autor trata este tipo de encontro como etapa rara de "trajetórias improváveis" que não difere substancialmente da seleção.

Uma vez integrado profissionalmente, o dançarino é estimulado por seus empregadores a se manter sob o estatuto de "temporário" (intermittent), o que possibilita alguns benefícios governamentais. As companhias de dança contam como certos os rendimentos oriundos desses benefícios ao definir suas remunerações. Entretanto, mudanças recentes na legislação trabalhista dificultaram a manutenção deste estatuto. O número de horas anuais de trabalho remunerado que asseguram o reconhecimento da condição de trabalhador temporário do espetáculo subiu para 507, o que contribuiu para que muitos dançarinos aceitassem cachês reduzidos. Além disso, necessidades financeiras fazem com que muitos dançarinos tenham outro emprego, o que dificulta a profissionalização por reduzir a disponibilidade para formação, exercício e contemplação da dança, bem como restringe a convivência com os pares. Assim, o risco de desvio profissional está direta e proporcionalmente relacionado com a distância entre atividades secundárias e a dança.
Comparado a outras atividades artísticas, o trabalho realizado por dançarinos não tem o mesmo prestígio que o de outros intérpretes, como atores de teatro, e sobretudo de cinema. $\mathrm{Na}$ dança contemporânea, o reconhecimento é bastante desigual. Os coreógrafos são identificados com o papel de criador, a partir do qual eles se valorizam como autores. Os dançarinos são tratados como quem interpreta papéis elaborados por terceiros, recebendo, portanto, pouco crédito sobre sua própria atuação. Assim, é raro destacar o nome de algum dançarino na divulgação ou na crítica de espetáculos. A elevada confiança no trabalho dos coreógrafos não é motivo suficiente para explicar o silêncio dos dançarinos quando o assunto é a desigualdade a que são expostos. Há um regime de dívidas e gratidões publicamente reconhecido que funda a autoridade dos coreógrafos.

Sob o mito da vocação para a qual os bons profissionais são tratados como que se nascessem predestinados, a dança demanda grande dedicação e leva à insegurança profissional. O desenvolvimento de escolas públicas atenuou as restriçōes e contribuiu para o prestígio e a ampliação do número de profissionais, elevando o excedente de dançarinos no mercado de trabalho. Assim, a discussão sobre direitos e remuneração é silenciada no mundo da dança. Sob fortes metáforas religiosas e níveis desiguais de reconhecimento, é difícil alterar a relação de forças, e os coreógrafos além de ser os "criadores", são considerados sobretudo empregadores e chefes, mesmo que as colaboraçóes artísticas dos dançarinos sejam decisivas para a concepção e a execução de um espetáculo. O poder dos coreógrafos avança sobre a intimidade das relaçóes interpessoais e alguns aproveitam essa condição para obter favores sexuais (p. 162).

Ao restituir experiências de intenso convívio com seus colegas, o autor trata de um trunfo da observação participante que contribui para fundamentar os argumentos de imbricação entre trabalho e lazer: o período em que dividiu moradia com uma dançarina e as turnês de que participou. Descrevendo uma jornada típica de um período de quatro meses de coabitação com a equipe de um espetáculo no interior da França, ele relata que, desde o despertar, às 8 horas, até o horário de dormir, 
por volta das 23 horas, eram raros os momentos de privacidade, exceto, durante o café da manhã, momento em que lia o jornal e conseguia se sentir cidadão do mundo. O nível intenso de convivência tornava difícil a estabilização de uma vida afetiva e social distante da dança.

Sorignet estabelece uma diferença entre os gêneros clássico e contemporâneo ao tratar dos estereótipos que associam a profissão às mulheres e aos homossexuais. O percurso típico do bailarino clássico começa na infância e leva a uma aprendizagem de conotação desvirilizante (p. 251). Os que persistem nesta carreira se socializam em contato com homossexuais. Em contrapartida, a dança contemporânea é geralmente descoberta na adolescência, em um meio que não é necessariamente marcado pela presença de professores ou colegas homossexuais. De qualquer forma, segundo o autor, o mundo da dança, como todo meio artístico, representa para os homossexuais a vivência de uma sexualidade livre de estigmas.

A necessidade de abandonar a dança devido ao envelhecimento é um tema que de maneira periférica perpassa todo o livro, mas o autor dedica o último capítulo para analisar mais detidamente esse processo e suas consequências na vida do dançarino. Ter que redefinir os rumos de seu trabalho ou mesmo mudar de profissão torna-se um fantasma para o artista; a mudança para muitos significa um grande sofrimento psicológico, o que dificulta sobremaneira a integração em outra condição profissional. São raros os casos de dançarinos que envelhecem atuando profissionalmente.

Por fim, cabe ponderar dois aspectos que só enriqueceriam o trabalho de Sorignet. Primeiro, a propósito ainda da ideia de juventude como possibilidade única para o exercício da profissão. Trata-se de uma noção que remonta à Antiguidade, em que se considerava a plenitude das capacidades físicas como absolutamente restrita à juventude. $\mathrm{O}$ autor poderia ter alargado seu campo de visão se não sustentasse tal perspectiva, isto é, poderia discutir na atualidade as inúmeras possibilidades artísticas para o dançarino que deixa de ser considerado jovem. Ainda que tenha destacado a trajetória de mulheres que dançaram praticamente até seus últimos dias de vida, So- rignet não consegue se desvencilhar da primazia da juventude. Como dançarino, ele certamente se distancia das noções clássicas, mas, como pesquisador, mantém-se fiel a essa visão.

Em segundo lugar, o autor restringiu-se ao exame dos papéis representados pelo dançarino, coreógrafo, professor e crítico, não explorando outros perfis de trabalhadores que habitam o mundo da dança, e que não são poucos. Isso certamente teria ampliado seu campo de análise.

Em seminário de apresentação do livro à Escola de Altos Estudos em Ciências Sociais, Sorignet afirmou que, devido à fatiga corporal, não fez anotaçōes diárias, ou seja, não realizou o que é estritamente considerado um "diário de campo". Em seguida convidou os ouvintes a pensar o que significa realmente tomar notas e, sobretudo, o que é fazer pesquisa de campo. Segundo ele, independentemente dos métodos escolhidos, a pesquisa em ciências sociais é sempre cumulativa e, portanto, incompleta. Uma metodologia que contribui para ascender a determinados conhecimentos, provavelmente limita outros. Neste estudo, o engajamento do pesquisador é, ao mesmo tempo, uma fortaleza e a origem de lacunas. Muitos outros aspectos sociológicos da dança contemporânea na França poderiam ter sido abordados, mas Sorignet enfatiza a relação entre dançarinos e coreógrafos porque, provavelmente, foi isso que o perturbou enquanto dançarino. Apesar desse tipo de lacuna, e talvez exatamente por isso, Danser: enquête dans les coulisses d'une vocation é uma referência tanto para quem estuda o mundo das artes, como para quem se aventura em uma observação participante visando à produção de conhecimento em ciências sociais.

\section{Nota}

1 Sorignet utiliza em diversas passagens dados produzidos pelo Deps e informações difundidas por outros serviços estatais do governo francês. Assim, ele busca em terceiros a fonte para os argumentos quantitativos que apresenta tanto para tratar de dançarinos, como do mercado de trabalho em geral. 


\section{BIBLIOGRAFIA}

BECKER, Howard S. (1984), Art worlds. Berkeley, University of California Press.

BOLTANSKI, Luc. (1971), "Les usages sociaux du corps". Annales ESC, 26 (1): 205-233.

DEPS - Département des Études, de la Prospective et des Statistiques. (2006), Les danseurs, un métier d'engagement. Paris, La Documentation Française.

MARCÍLIO DANTAS BRANDÃO é doutorando em sociologia na EHESS-

Paris. E-mail: <marcilio.brandao@ehess.fr>. 